\title{
Impact of Time, Oxygen and Different Anthocyanin to Tannin Ratios on the Precipitate and Extract Composition Using Liquid Chromatography-High Resolution Mass Spectrometry
}

\author{
G. Garrido-Bañuelos ${ }^{1 \#}$, A. Buica ${ }^{1 *}$, A. de Villiers ${ }^{2}$, W.J. du Toit ${ }^{1}$ \\ (1) Department of Viticulture and Oenology, Stellenbosch University, Private Bag X1, Matieland 7062, South Africa. \\ (2) Department of Chemistry and Polymer Science, Stellenbosch University, Private Bag X1, Matieland 7062, South Africa.
}

Submitted for publication: October 2018

Accepted for publication: November 2018

Keywords: wine-like extract, precipitate, anthocyanin to tannin ratio, oxygen, HRMS fragments identification

\begin{abstract}
Wine colour and phenolic stability over time are influenced by the amount and nature of phenolics in young wines. The ratio between different phenolic compounds can also be determinant in the colour and phenolic development of red wines. Three different anthocyanin to tannin ratios extracted in a wine-like system were saturated with oxygen several times during sample storage. A LC-HRMS method was used to evaluate the impact of a forced oxidation and of the different extracts on the wine-like composition and on the precipitate formed over time. The extract composition was found to be the most determinant factor for the precipitate formed. Time was also found to be a relevant factor according to the precipitate composition.
\end{abstract}

\section{INTRODUCTION}

The production of red wines with good ageing potential is important to the global wine industry. A large number of biological interactions and chemical reactions during the winemaking process and storage can lead to changes in the composition and stability of red wines (Arapitsas et al., 2016; Ribéreau-Gayon, Glories, Maujean, \& Dubourdieu, 2006). Red wine's colour and phenolic stability are essential parameters which are directly related to consumer acceptance of the product. The wine matrix composition is also playing a role in influencing the wine stability. As an important part of the wine matrix, phenolic compounds are involved not only in affecting a red wine colour, but also in certain sensory properties. Wine phenolics are highly reactive molecules, partaking in different reactions from crushing throughout the entire winemaking process, which may lead to the formation of more complex and stable molecules over time (Arapitsas, Speri, Angeli, Perenzoni, \& Mattivi, 2014; Bimpilas, Tsimogiannis, Balta-Brouma, Lymperopoulou, \& Oreopoulou, 2015; Monagas, GómezCordovés, \& Bartolomé, 2006; Pérez-Magariño \& GonzálezSanJosé, 2004). Different winemaking techniques can thus have an indirect impact on a wine's stability as these may also influence phenolic extractability and evolution (Sacchi, Bisson, \& Adams, 2005; Smith, McRae, \& Bindon, 2015).

Anthocyanins, mainly responsible for the colour in young red wines (He et al., 2012; Ribéreau-Gayon et al., 2006), are extracted from the grape skins, whereas grape tannins are extracted from both skins and seeds. Skin and seed tannins differ in nature, structure, and extractability (Mattivi, Vrhovsek, Masuero, \& Trainotti, 2009). Whilst anthocyanin concentrations normally reach a maximum during the early stages of the alcoholic fermentation, tannins are progressively extracted as the ethanol concentration increases (González-Manzano, Rivas-Gonzalo, \& SantosBuelga, 2004; Peyrot Des Gachons \& Kennedy, 2003; Ribéreau-Gayon et al., 2006). Moreover, as is the case with anthocyanins, skin tannin levels reach a plateau during fermentation, whereas seed tannins follow a linear extraction partly due to the hydration of the seed coat (Cerpa-Calderón \& Kennedy, 2008; Hernández-Jiménez, Kennedy, BautistaOrtín, \& Gómez-Plaza, 2012; Yacco, Watrelot, \& Kennedy, 2016). The initial anthocyanin to tannin ratio (A/T) will affect the subsequent wine polymerisation reactions (Singleton \& Trousdale, 1992; Sparrow, Dambergs, Bindon, Smith, \& Close, 2015) and the interaction of phenolic compounds with other wine components (Bindon, Smith, \& Kennedy, 2010; Springer, Chen, Stahlecker, Cousins, \& Sacks, 2016). The ratio of anthocyanins to tannins may therefore not only affect the wine's stability, but also its sensory properties (Canals, Llaudy, Miquel, \& Fernando, 2008). Techniques such as early seed removal or the addition of mannoproteins (Poncet-Legrand, Doco, Williams, \& Vernhet, 2007) are used as winemaking practices to alter the skin/seed tannin ratio, thereby trying to reduce the bitterness (associated with

\footnotetext{
*Corresponding author: E-mail address: abuica@sun.ac.za

\# Product Design and Perception, RISE Research Institutes of Sweden-Agrifood and Bioscience, Box 5401, S-402 29, Göteborg, Sweden Acknowledgments: The authors would like to thank Winetech and NRF for financial support
} 
seed tannins) in the final red wines (Lee, Kennedy, Devlin, Redhead, \& Rennaker, 2008; Meyer \& Hernandez, 1970).

Apart from the initial phenolic content, several other factors like the presence of oxygen, will influence the evolution of red wine over time. Indeed, oxygen is thought to play a crucial role in red wine's colour and phenolic stabilization during the entire winemaking process (Du Toit, Marais, Pretorius, \& Du Toit, 2006). It is involved in several reactions, such as phenolic polymerization, which leads to the formation of new and more stable phenolic compounds over time (Atanasova, Fulcrand, Cheynier, \& Moutounet, 2002; Fulcrand, Cameira dos Santos, Sarni-Manchado, Cheynier, \& Favre-Bonvin, 1996). Oxidation of ethanol produces acetaldehyde, which enhances the formation of ethyl-bridges between phenolics (Dallas, Ricardo-daSilva, \& Laureano, 1996; Es-Safi, Fulcrand, Cheynier, \& Moutounet, 1999; Saucier, Bourgeois, Vitry, Roux, \& Glories, 1997; Timberlake \& Bridle, 1977). Additionally, the oxidative degradation rate differs between the different groups of phenolics. For example, as shown in a study by Jorgensen et al., (2004), skin procyanidins degrade faster than those extracted from the seeds in the presence of oxygen (Jorgensen et al., 2004). The impact of oxygen on altered $\mathrm{A} / \mathrm{T}$ ratios in wine has been shown to improve the colour density (CD) and the polymeric pigment concentration as the tannin content increases (Picariello, Gambuti, Picariello, $\&$ Moio, 2017). Thus, the impact of oxygen will probably vary as a function of the nature and relative ratios of the wine phenolics. Although the impact of oxygen on wine phenolics has extensively been examined (Arapitsas et al., 2012; Atanasova et al., 2002; Castellari, Matricardi, Arfelli, Galassi, \& Amati, 2000; McRae et al., 2015; Quaglieri, Jourdes, Waffo-Teguo, \& Teissedre, 2017)especially that of anthocyanin-derived pigments, has helped improve wine quality over the years. The use of micro-oxygenation (MOX, only two recent publications have evaluated the effect of oxygen on different anthocyanin/tannin ratios (Carrascón et al., 2018; Picariello et al., 2017).

There are still lot of unknowns regarding the complexity and the different structures of phenolic compounds, especially tannins, in grapes and wine. In this regard, the continuous development of more powerful analytical methods and techniques is leading to the generation of larger datasets with valuable information for wine science. As an example, the use of different methods of High Resolution Mass Spectrometry (HRMS) and Liquid Chromatography High Resolution Mass Spectrometry (LC-HRMS) have provided a powerful tool in the research of phenolic compounds in different food matrices (Lucci, Saurina, \& Núñez, 2017; VallverdúQueralt et al., 2017; Zeng, Teissèdre, \& Jourdes, 2016). The aim of this study was to assess the impact of different $\mathrm{A} / \mathrm{T}$ ratios and forced oxidation on a wine-like system and the precipitate formed over time. To our knowledge, only two previous studies analysed the composition of the phenolic derived precipitate formed in red wines (Prakash, Iturmendi, Grelard, Moine, \& Dufourc, 2016; Waters et al., 1994), but this is the first time that the precipitation phenomena as a consequence of different phenolic ratios is studied. In short, the present work, based on untargeted approaches, evaluated and tentatively identified the main compounds driving the differences between the wine-like composition and the precipitate that was formed over time.

\section{MATERIALS AND METHODS \\ Wine-like extracts}

Shiraz grapes $\left(27^{\circ}\right.$ Brix $)$ were obtained in 2015 from the Welgevallen experimental vineyard (GPS coordinates: $33^{\circ} 56^{\prime} 25.0^{\prime \prime S} 18^{\circ} 51^{\prime} 56.4^{\prime \prime E}$ ) of the Department of Viticulture and Oenology at Stellenbosch University, South Africa. From preliminary trials it was determined that the amount of grape seeds was the main variable in the treatments. In order to achieve different $\mathrm{A} / \mathrm{T}$ ratios, the experimental design included different skin to seed proportions. The main variable, normal seed to skin ratio, was established from the average weight of the skin and seeds, of the Shiraz grapes harvested for the present project. Practically, grape skins $(240 \mathrm{~g})$ were peeled off and manually separated from the flesh and seeds, rinsed with deionised water and extracted with or without seeds according to the seed to skin ratios (no seeds - SK, normal seed to skin ratio - SKSD, and four times the normal seed to skin ratio - SK4SD) for nine days in $1 \mathrm{~L}$ hydroalcoholic solution (15\% ethanol), at $\mathrm{pH} 3.4$ and containing $6.0 \mathrm{gL}-1$ tartaric acid. A single extraction was performed per $\mathrm{A} / \mathrm{T}$ ratio. The extractions were carried at $25^{\circ} \mathrm{C}$ and manually shaken three times per day. To avoid the possibility of any spoilage, $20 \mathrm{mgL}-1 \mathrm{NaN} 3$ (Sigma-Aldrich - St. Louis, MO, USA) were added to the extracts. After nine days, the skins and seeds were separated from their extracts and softly pressed by hand (in the presence of $\mathrm{CO} 2$ ). The three final wine-like extracts (SK, SKSD, and SK4SD) were then centrifuged at $8000 \mathrm{rpm}$ ( $5 \mathrm{~min})$, to remove any residual grape skin. The iron and copper concentrations were then adjusted to $5 \mathrm{mgL}-1$ and $0.3 \mathrm{mgL}-1$ respectively with the use of FeSO4.7H2O and CuSO4.5H2O (Sigma-Aldrich - St. Louis, MO, USA) according to Danilewicz (2007). After the nine days of extraction, the tannin levels were different between the three extracts: $450.99 \mathrm{mg} / \mathrm{L}$ for SK, 587.86 for SKSD and $1092.77 \mathrm{mg} / \mathrm{L}$ for SK4SD (Garrido-Bañuelos, 2018). Tannin concentration (expressed in catechin equivalents) was determined by methyl cellulose precipitation (Sarneckis et al., 2006)50\% ethanol grape extract and aqueous tannin solutions. By exploiting the polysaccharide polymer methyl cellulose to precipitate tannins, the absorbance of phenolics at $280 \mathrm{~nm}$ before and after tannin precipitation (subtractive approach. Finally, the extracts were divided into Control (C) and Oxygen treatments $(\mathrm{Ox})$ and transferred to vials (20 mL vials for $\mathrm{C}$ and $100 \mathrm{~mL}$ vials for $\mathrm{Ox}$ ) and sealed hermetically. $\mathrm{C}$ vials were previously filled with nitrogen. Then, the $\mathrm{C}$ treatments were transferred into the vials using $\mathrm{CO}_{2}$ gas. On the other hand, before being transferred to the vials, Ox samples were vigorously shaken by hand in a 500 $\mathrm{mL}$ volumetric flask for 2 minutes allowing air to enter every 10 seconds to reach oxygen saturation in the sample. The oxygen consumption in Ox samples, and the absence of oxygen in $\mathrm{C}$ were monitored with the use of oxygen spots (Pst3, PreSens, Regensburg, Germany) during the first 70-75 hours. The data regarding the oxygen consumption patterns is not shown in this paper (Garrido-Bañuelos, 2018). All vials were stored in the dark at $15^{\circ} \mathrm{C}$ until the required analysis after $6(6 \mathrm{M})$ and 9 months $(9 \mathrm{M})$ of storage. Once opened 
and analysed, $\mathrm{C}$ treatments vials were discarded whereas in the case of Ox samples, $20 \mathrm{~mL}$ were drawn from the vials and the remainder again saturated with oxygen before further storage. The precipitates formed over time in all the treatments were recovered after $6 \mathrm{M}$ and $9 \mathrm{M}$. After $6 \mathrm{M}$, Ox samples were transferred to new vials allowing for the recovery of the precipitate formed from their corresponding extracts at this specific sample stage. Glass beads were used to fill the headspace in the Ox vials at each of the sampling stages. The precipitate was recovered and placed it in a fume hood to dry. Once the precipitate was dry it was dissolved in $5 \mathrm{~mL}$ methanol.

\section{Liquid Chromatography High Resolution Mass Spec- trometry (LC-HRMS)}

The wine-like extracts their corresponding precipitate samples were all analysed. A sample volume of $2 \mu \mathrm{L}$ was injected into a Synapt G2 quadrupole-time-of-flight (Q-TOF-MS) mass spectrometer (Waters Corporation). The separation was performed on an Acquity UPLC HSS T3 column (1.8 $\mu \mathrm{m}$ internal diameter, $2.1 \mathrm{~mm} \times 100 \mathrm{~mm}$, Waters Corporation) using $0.1 \%$ formic acid (mobile phase A) and acetonitrile (mobile phase B) and a scouting gradient, from $5 \%$ to $100 \% \mathrm{~B}$, with a flow rate of $0.3 \mathrm{mLmin}^{-1}$. The column temperature was $55^{\circ} \mathrm{C}$. The instrument was operated with an electrospray ionization (ESI) probe in both positive and negative mode. Data acquisition was performed in $\mathrm{MS}^{\mathrm{e}}$ mode which consisted of a low collision scan (from m/z 150 to 650 ) and a high collision energy scan (from $\mathrm{m} / \mathrm{z} 40$ to 650 ), using a ramp of 30-60 V. The MS parameters were optimized for best sensitivity as follows: cone voltage $15 \mathrm{~V}$, nitrogen desolvation gas at $650 \mathrm{Lhr}^{-1}$ and desolvation temperature $275^{\circ} \mathrm{C}$. The data was obtained as $\mathrm{RT} \mathrm{m} / \mathrm{z}$, intensity, using MassLynx (v. 4.1) software (Waters, Milford, MA, USA). All solvents used for analysis were LC-MS grade. Acetonitrile and formic acid were purchased from Merck (Darmstadt, Germany). Deionised water was obtained from Milli-Q water purification system (Millipore, Milford, MA, USA). The different wine-like extract treatments were analysed in triplicate.

\section{Statistical analysis}

The MS data generated was analysed using MarkerLynx XS (Waters Corporation), an application manager that performs 3D peak integration, data set alignment and incorporates multivariate statistical tools. Chromatographic data was extracted as (RT $m / z$, intensity) matrix by MarkerLynx XS. The software is directly integrated with SIMCA and the statistical algorithms are directly applied to the processed data sets. All Principal Component Analysis (PCA), Orthogonal Partial Least Squares Discriminant Analysis (OPLS-DA) and their corresponding S-plots were performed with SIMCA 14.1 software (Sartorium Stedim Biotech Malmö, Sweden).

\section{RESULTS AND DISCUSSION}

Untargeted MS analysis was used to evaluate the impact of the different variables (extract composition, oxygen and time) on the stability of the phenolic compounds in solution. Discriminant analyses were performed using this dataset to find which fragments were influenced by these various parameters. A large dataset was generated from the WL and P samples analysed with LC-HRMS. PCA was used to explore the sample distribution according to the MS dataset generated. Firstly, the PCA plot illustrated in Figure 1 (A) shows a clear separation along PC2 (7.45\%) between the two different matrices, wine-like extract and precipitate, according to their chemical composition. The low explained variance found in the PCA plot is due to a consequence of the large number of ions detected in both matrices.

With the aim to further tentatively identify the fragments driving the differences between samples, discriminant analyses were performed on wine-like and precipitate data independently. With this in mind, Orthogonal Partial Least Square Discriminant Analysis (OPLS-DA) is a more powerful technique as it concentrates the variance and was therefore used for this purpose. To evaluate the individual impact of the different variables, the corresponding S-Plots (scaled to Pareto variance), were constructed based on pairwise comparisons (i.e. SK vs. SKSD; SK vs. SK4SD or SKSD $v s$. SK4SD). The S-plots are a screening tool frequently used to target/identify the possible markers contributing specifically to each treatment. These potentially distinctive markers are generally distributed on the "S"-wings of the plot (upper-right and lower-left edge of the plot). From then, a list of fragments which may influence the phenolic stability and precipitation was generated. The CV-ANOVAs for the different pair-wise comparisons were performed to assess model reliability (Worley \& Powers, 2016) (Supplementary Table 1).

Some of the ions/fragments were found in both matrices, wine-like extract and precipitate. Their presence in the precipitate may be explained as result of the fragmentation of a larger molecule during the ionization. Nevertheless, an OPLS-DA and the corresponding S-Plot were generated to visualise which ions might be driving the main differences between the two matrices (Figure 1 B1 and B2). From the S-plot (Figure 1 B2), the ions considered as the main contributors, but not the only ones, driving the differences between the matrices were $\mathrm{m} / \mathrm{z} 477,507,637$ and $655 \mathrm{~m} / \mathrm{z}$ for the precipitate (lower side of the $\mathrm{S}$ ) and 177, 191 and 605 for the wine-like (upper side of the $\mathrm{S}$ ). Tentative assignment of these influential ions to specific compounds was based on accurate mass data, low and high collision energy MS spectra and relative RP-LC elution order in comparison with an internal library and reported literature (Alberts, Stander, \& Villiers, 2012; De Rosso, Panighel, Vedova, Gardiman, \& Flamini, 2015; Monagas, Bartolomé, \& Gómez-Cordovés, 2005).

As shown in Table 1, the ions found in the wine-like extracts and distinguishing from the precipitate, were identified as gluconolactone $(\mathrm{m} / \mathrm{z} 177)$, citric acid $(\mathrm{m} / \mathrm{z} 191)$ and a hemicellulose derivative $(\mathrm{m} / \mathrm{z} 605)$. In previous studies, the presence of polysaccharides and proteins was reported in the precipitate formed in bottles and wine barrels (Prakash et al., 2016; Waters et al., 1994). Nevertheless, the presence of some cell wall polysaccharide derivatives in solution could be relevant to obtain a better understanding on how the different grape polysaccharides influence wine stability. On the other hand, $\mathrm{m} / \mathrm{z} 477$ (petunidin glucoside), $\mathrm{m} / \mathrm{z}$ 


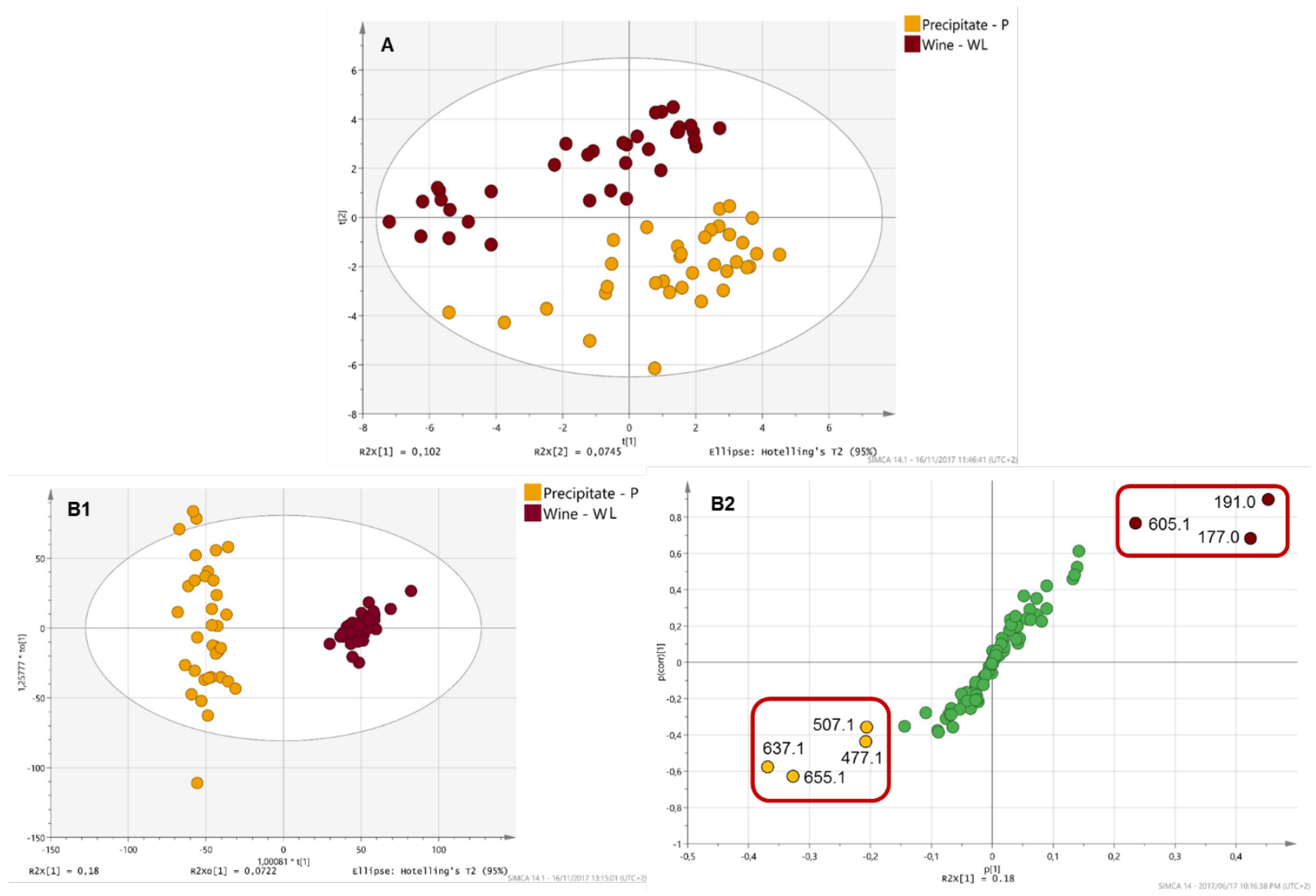

FIGURE 1

PCA (A), OPLS-DA (B1) and corresponding S-Plot (B2) comparing the two different matrices (WL and P) according to the different ions analysed by LC-HRMS.

507 (syringetin-hexoside), $\mathrm{m} / \mathrm{z} 637$ (malvidin-coumaroylglucoside) and $\mathrm{m} / \mathrm{z} 655$ (its carbinol form) were identified in the precipitate (Table 1), indicating a loss of colour over time is at least partially due to precipitation of anthocyanins (data not shown, Garrido-Bañuelos, 2018).

With regards to the specific differences between the different wine-like composition, the CV-ANOVA analysis showed that only the models built between the different extracts were statistically significant $(\mathrm{p}<0.05)$. The models built for $\mathrm{C} / \mathrm{Ox}$ and time were not statistically significant. The graphs in Figure 2 show the cross-validated OPLSDA plots and their corresponding S-plots for the different pair comparisons between the extracts (SK $v s$. SKSD; SK $v s$. SK4SD or SKSD vs. SK4SD). The ions selected can be considered as the major contributors driving the differences between the extracts. A maximum of five ions were selected when a large number of ions were found on the edge of the $\mathrm{S}$ plot (like in Figure $2 \mathrm{C} 2$ ). Firstly, from SK vs. SK4SD (Figure 2 A2) and SK vs. SKSD (Figure 2 B2), the $m / z 177$ and 341 were only present in SK treatments. On the other side, the following ions: $m / z 169,197,229$ and 331 were found to appear on the upper-right edge of the S plot, as seed derived compounds were part of the extract (Figure 2 A2 and B2). Furthermore, a few other ions were selected from the pair-wise comparisons performed between SKSD and SK4SD. As represented in Figure 2 C2, the ion $177 \mathrm{~m} / z$ was found on SKSD (lower-left side) whereas $m / z$ 169, 229, 331 were found again in the SK4SD side, together with other ions such as $m / z 347$ and 443 . The formation of gluconolactone ( $m / z$ 177), naturally found in some food products and as an additive in cosmetics, had previously been reported in studies wine-like system (Bertrand \& Barbe, 2002). Its formation is related to the presence of gluconic acid in solution, an oxidised by-product of glucose. Additionally, caffeic acid3-O-glucoside nor caffeic acid-4-O-glucoside $(\mathrm{m} / \mathrm{z} 341)$ was also found in solution when comparing SK vs. SKSD. On the other hand, some of the ions selected from the treatments with the presence of seeds were related to seed derived compounds rich in fragments such as gallic acid (m/z 169), ethyl gallate $(\mathrm{m} / \mathrm{z} 197)$ and a gallic acid-glucoside $(\mathrm{m} / \mathrm{z} 331)$. Additionally, when comparing SK4SD versus SKSD, a gallic acid derivative $(\mathrm{m} / \mathrm{z} 331)$ was also identified. However, the identity of the ions $\mathrm{m} / \mathrm{z} 229$ and 443 remains unknown.

Although not significant, the cross-validated OPLSDA models and the corresponding S-Plots evaluating the impact of oxygen and time were also performed in the wine-like extracts (data not shown). Interesting results were also obtained, such as the occurrence of methyl gallate $(\mathrm{m} / \mathrm{z}$ 183 ) in C samples, compared to the presence of quercetinglucoside $(\mathrm{m} / \mathrm{z} 369)$ in the Ox samples (Table 1).

Interesting results were also obtained from the discriminant analysis performed on the precipitate data 


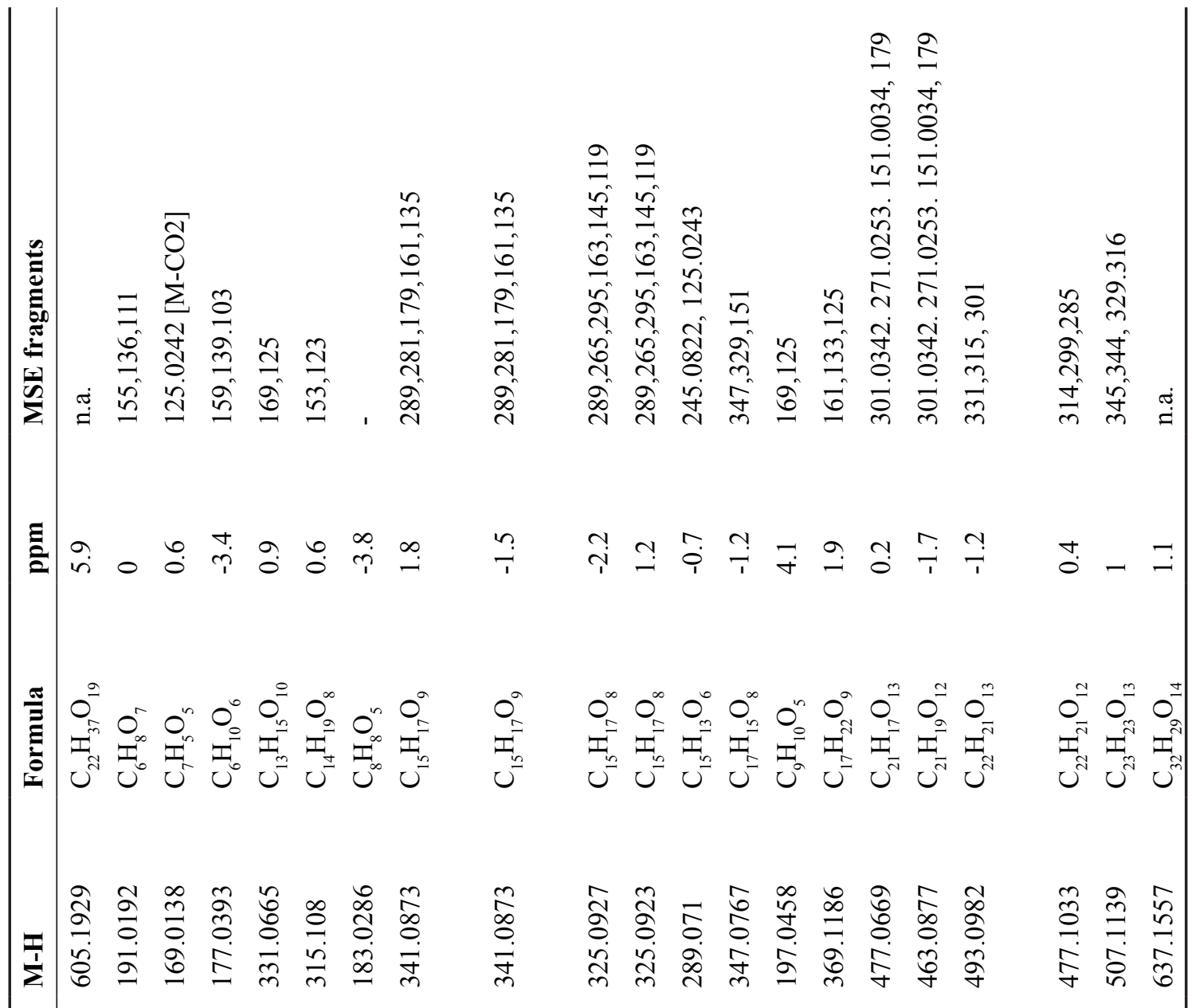

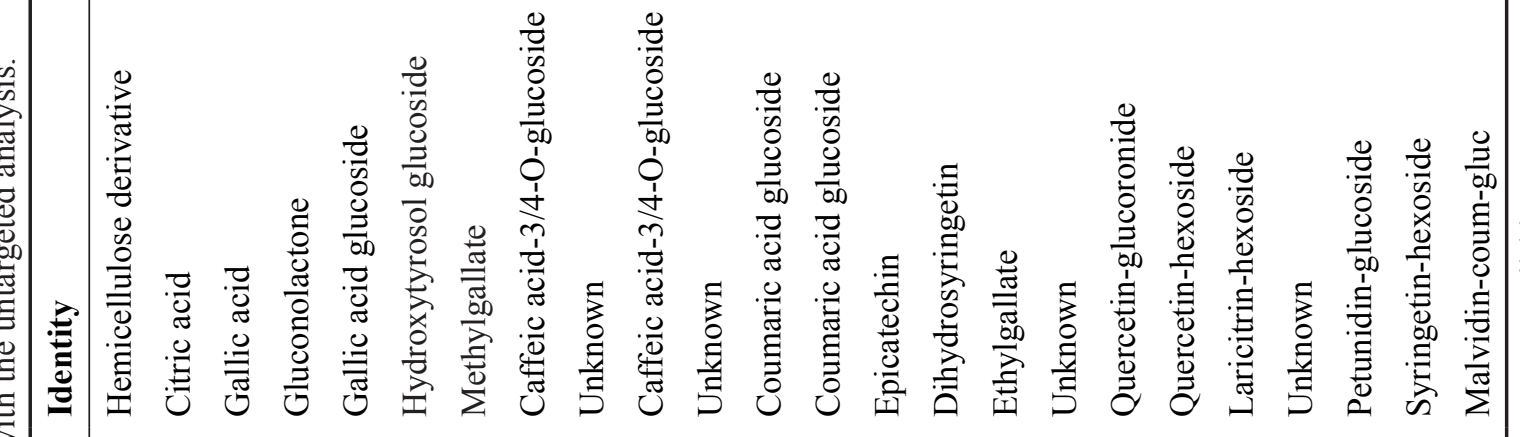

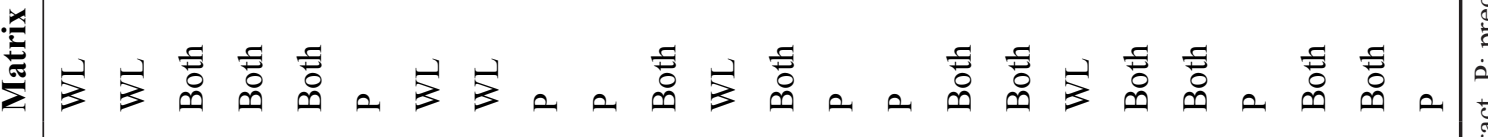



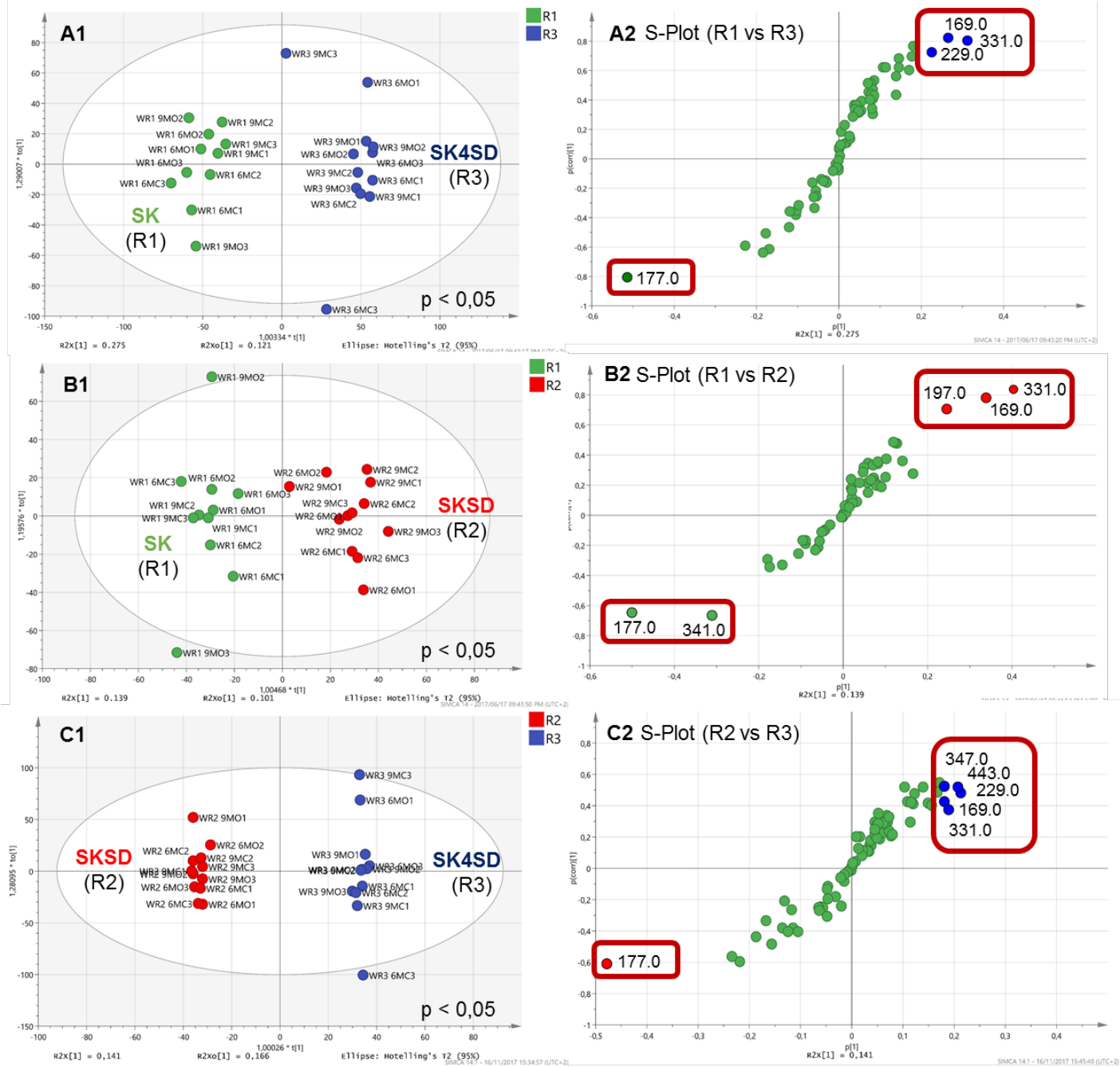

FIGURE 2

OPLS-DA and S-Plot pair-wise comparisons between the different A/T ratios on the WL. R1, R2 and R3 represent the SK, SKSD and SK4SD respectively. A1 and A2 represents the OPLS-DA plot and S-plot between SK and SK4SD. B1 and B2 compared SK vs. SKSD. C1 and C2 compared SKSD vs. SK4SD.

(Figure 3). Vintage and cultivar have been found to be important factors influencing wine stability and the precipitate formed (Prakash et al., 2016). These two variables are known to influence the phenolic proportions but to our knowledge, this is the first study that evaluated the composition of a wine precipitate influenced by specific extract composition. However, the impact of the different extracts was found to be significant only for pair-wise comparisons between SK and SK4SD (Figure 3 A2). The statistical results indicated a role of the grape seed derived compounds not only in the concentration, but also on the stability of certain compounds in a wine like system. Firstly, $369 \mathrm{~m} / \mathrm{z}$ was found on the lower-left side of the S-plot (SK) from Figure 3 A2 and B2. The excess of seeds (SK4SD) led to the precipitation of the molecules with the following $\mathrm{m} / \mathrm{z}: 169,197,229,331$ and 493. The ion $m / z 369$ remains unknown. On the other side of the S-plot, the excess of seed (SK4SD) led to the precipitation of specific fragments which were also identify in the extracts, such as gallic acid $(\mathrm{m} / \mathrm{z} 169)$, ethyl gallate $(\mathrm{m} / \mathrm{z}$ $197)$ and a gallic acid derivative $(m / z 331)$. As mentioned, their presence in both, extract and precipitate samples may be due to a possible fragmentation of a larger molecules. The ion $\mathrm{m} / \mathrm{z} 493$ (Table 1) was identified as laricitrin-hexoside.

Moreover, contrary to the results in the wine-like extract, the cross-validated OPLS-DA and S-Plot defined time as a significant factor in the compound precipitation. The oxygen as a factor was not significant. From the S-plot $6 \mathrm{M} v s$. 9M (Figure 4), a few selected ions $(\mathrm{m} / \mathrm{z} 315,507$, 637 , and 655) originating from compounds that precipitated after $6 \mathrm{M}$ whilst 177,325 and $341 \mathrm{~m} / \mathrm{z}$ seemed to precipitate after $9 \mathrm{M}$. Then, over the course of time, malvidin-coumarylglucoside and its carbinol form precipitated after 6M, as well as hydroxytyrosol-glucoside $(\mathrm{m} / \mathrm{z} 315)$ (glucosylated of the bioactive compound hydroxytyrosol found in wine) and syringetin $(\mathrm{m} / \mathrm{z}$ 507). A recent study has evaluated the impact of hydroxytyrosol addition in Syrah wines, as alternative to $\mathrm{SO}_{2}$ with the result of an improvement in the wine colour at bottling (Raposo et al., 2016). The present of this fragment in the precipitate samples may be linked to the loss of colour overtime (data not shown, Garrido-Bañuelos, 2018). 

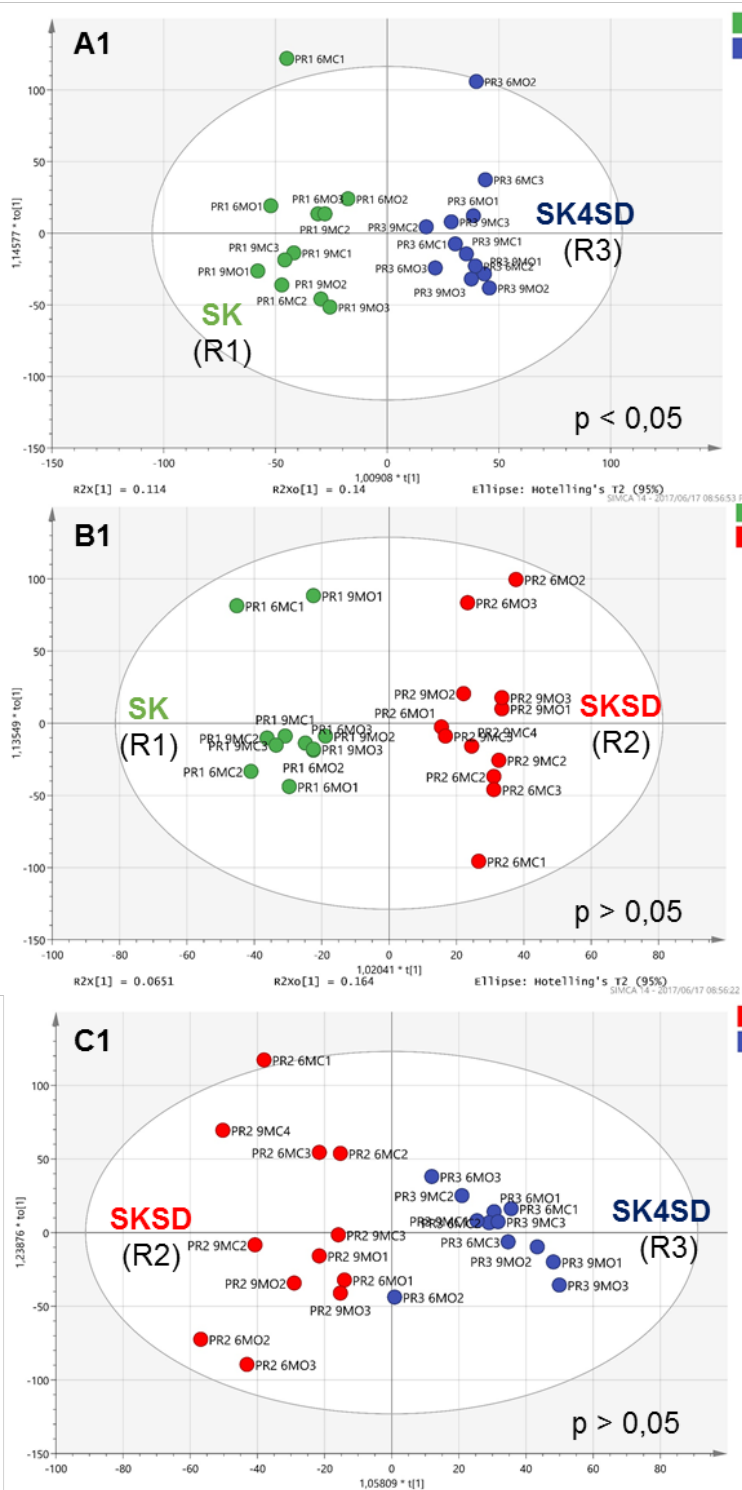

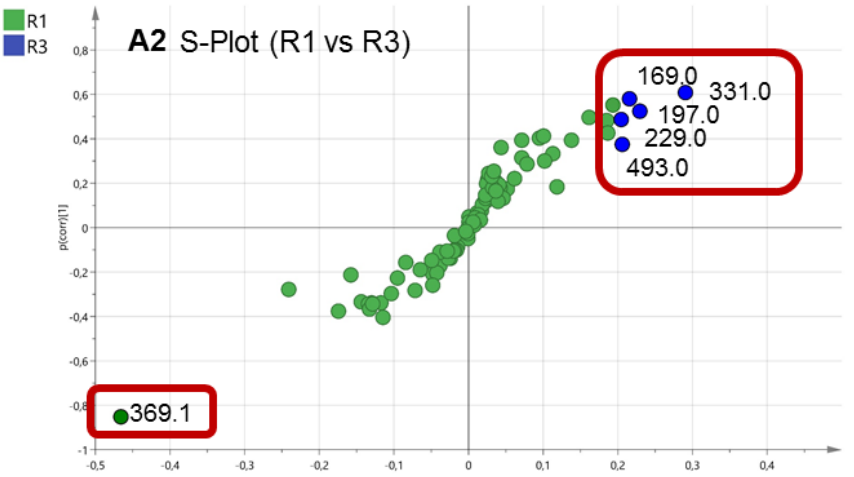

B2 S-Plot (R1 vs R2)
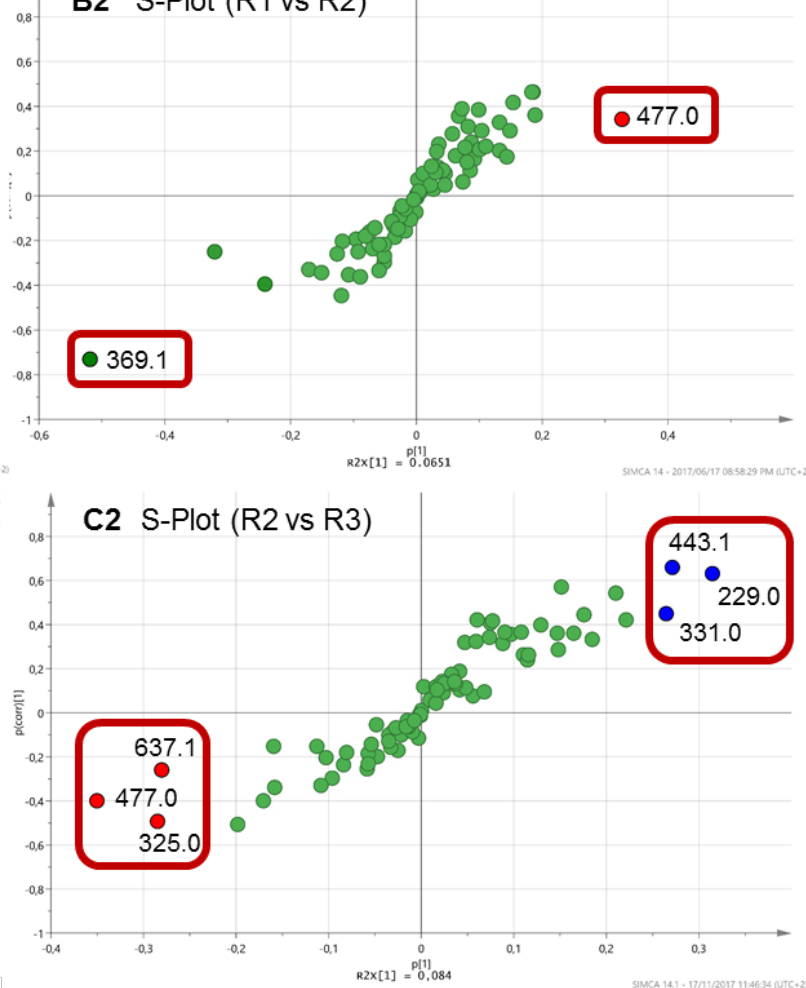

FIGURE 3

OPLS-DA and S-Plot pair-wise comparisons between the different A/T ratios on the P. R1, R2 and R3 represent the SK, SKSD and SK4SD respectively. A1 and A2 represents the OPLS-DA plot and S-plot between SK and SK4SD. B1 and B2 compared SK vs. SKSD. C1 and C2 compared SKSD vs. SK4SD.

Interestingly, some hydroxycinnamic acids derivatives only precipitated after 9M, such as the caffeic acid-3-O-glucoside nor caffeic acid-4-O-glucoside $(\mathrm{m} / \mathrm{z} 341)$ or coumaric acid glucoside $(\mathrm{m} / \mathrm{z} 325)$.

A few ions were also selected from the C/Ox S-plot (although the model was not significant) as they were clearly located on the S wings. As illustrated in Figure 5, malvidincoumaryl-glucoside $(637 \mathrm{~m} / \mathrm{z})$ was found in C samples. On the side the ions 463,477 and $507 \mathrm{~m} / \mathrm{z}$ were selected originating from fragments of the compounds that were precipitated in the presence of oxygen. Quercetin-hexoside $(\mathrm{m} / \mathrm{z} 463)$, petunidin glucoside $(\mathrm{m} / \mathrm{z}$ 477, RT 19.83) and syringetin $(\mathrm{m} / \mathrm{z}$ 507) were found in the Ox precipitate. The presence of $\mathrm{m} / z 637$ in C samples suggest a possible indirect protective effect of oxygen towards certain monomeric anthocyanins, by favouring the polymerisation reactions between other components in the media, during the first months of storage under our conditions (Garrido-Bañuelos, 2018).

Overall, the results from the present study showed a greater influence of the extract composition than oxygen on the evolution of the wine-like extract and the corresponding precipitate formed over time. In the presence of seeds, several fragments related to gallic acid derivatives were found in both matrices, extracts and precipitate. From a statistical point of view, the excess of seeds was found to be relevant in the wine-like stability and the precipitate formed, as the pair-wise comparison between SK and SKSD was not found to be significant. An excess of seed derived compounds, with a high reactivity to polymerise (Garrido-Bañuelos, 2018), can lead to the formation of larger molecules, not stable in solution. Time was found to be a significant factor influencing the precipitate formed. 

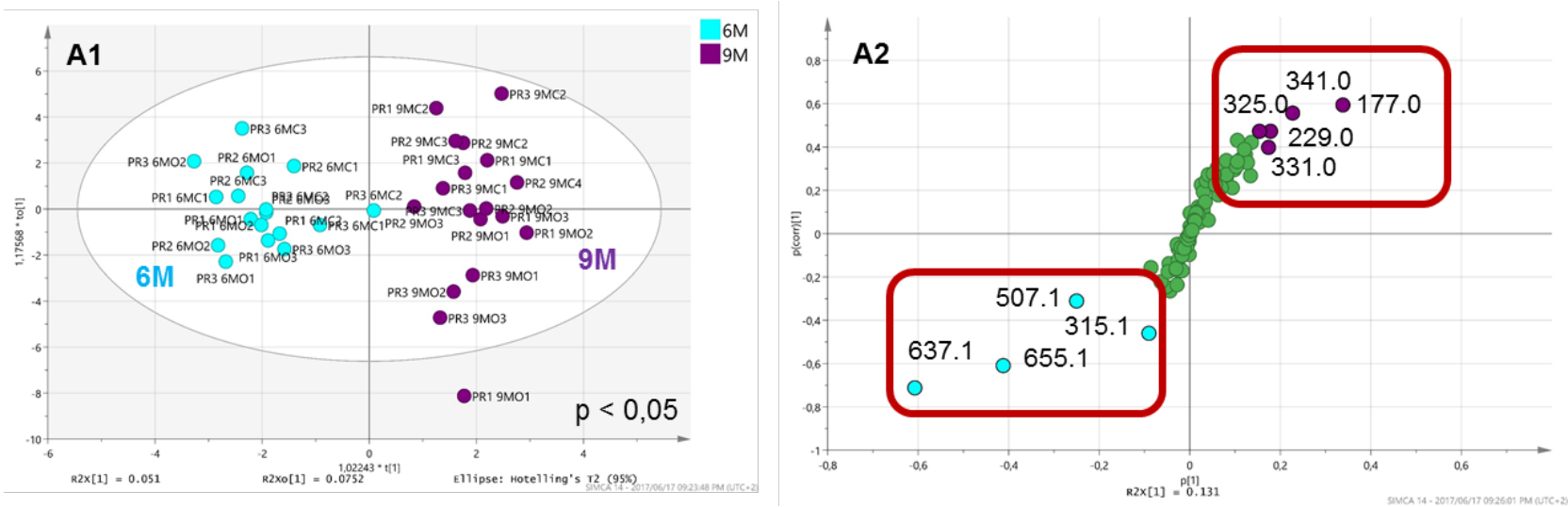

FIGURE 4

OPLS-DA (A1) and S-Plot (A2) pair-wise comparisons according to the precipitation time (6M vs.9M) on the P.
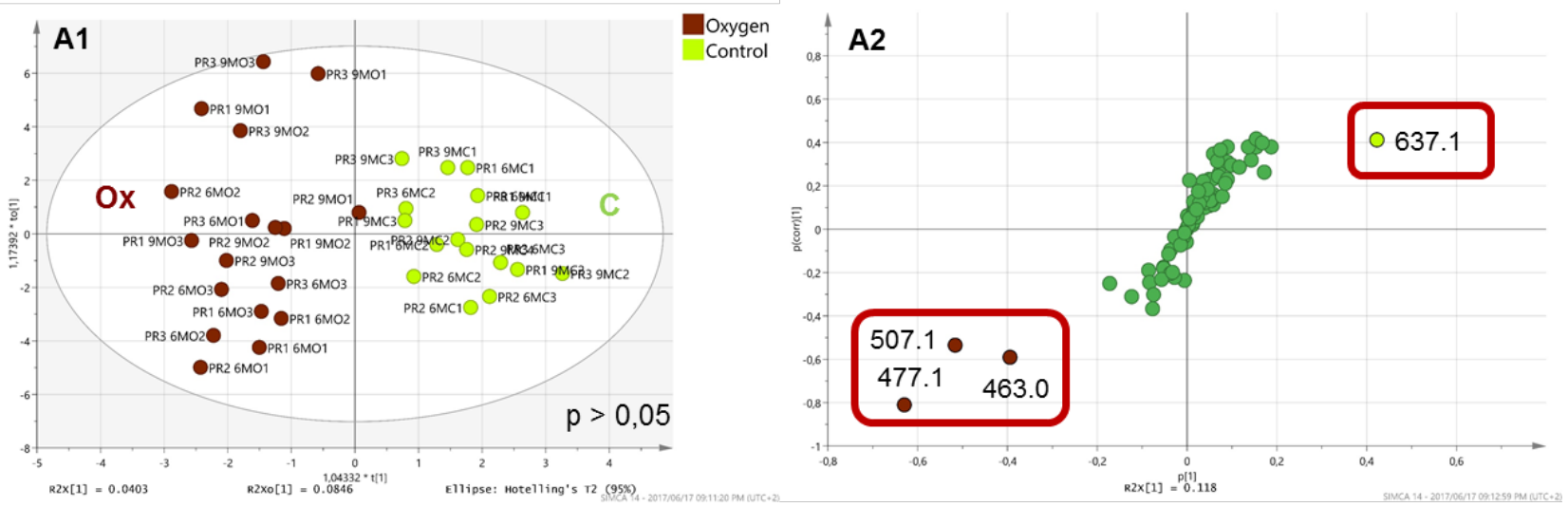

FIGURE 5

OPLS-DA (A1) and S-Plot (A2) pair-wise comparisons according to the C and Ox samples on the P.

\section{CONCLUSIONS}

The goal of the experiment was to assess the impact of the oxygen on three $\mathrm{A} / \mathrm{T}$ ratios in a WL system and the precipitate formed. In this sense, the present study also showed the influence of oxygen and a greater tannin content on the stability of certain compounds in a WL. To date, a large number of studies had focused on the impact of seed addition or removal on the colour, phenolic profile and sensory properties of the wines (Canals et al., 2008; Guaita et al., 2017; Lee et al., 2008; Meyer \& Hernandez, 1970), but there is a lack of information on their evolution and how oxygen influences this. The results in the present study highlight the importance of the initial phenolic composition in the evolution over time. This work has been carried in a model wine solutions. Nonetheless, in a red winemaking process, the presence of other grape or yeast derived compounds, such as proteins or polysaccharides, may alter this self-aggregation, polymerisation and precipitation reactions (Poncet-Legrand et al., 2007; Watrelot, Schulz, \& Kennedy, 2017).

The $\mathrm{A} / \mathrm{T}$ ratios with an excess of seeds were characterised by a larger number of gallic acid derivatives in solution, but also these were found in the precipitate. To our knowledge, this is the first time that the precipitation of phenolic compounds, as a consequence of altered $\mathrm{A} / \mathrm{T}$ ratio and forced oxidation, was examined. Further studies should investigate not only the impact of the grape seeds on the wine stability, but also on their role on the phenolic extractability and soluble grape cell wall polysaccharides during wine red fermentation.

\section{LITERATURE CITED}

Alberts, P., Stander, M.A. \& Villiers, A. De., 2012. Advanced ultra high pressure liquid chromatography - tandem mass spectrometric methods for the screening of red wine anthocyanins and derived pigments. J Chromatogr A. Elsevier B.V. 1235, 92-102.

Arapitsas, P., Corte, A. Della., Gika, H., Narduzzi, L., Mattivi, F. \& Theodoridis, G., 2016. Studying the effect of storage conditions on the metabolite content of red wine using HILIC LC-MS based metabolomics. Food Chem. 197, 1331-40.

Arapitsas, P., Scholz, M., Vrhovsek, U., Blasi, S. Di., Biondi, A., Masuero, D., Perenzoni, D., Rigo, A. \& Mattivi, F., 2012. A Metabolomic Approach to the Study of Wine Micro- Oxygenation. PLoS ONE. 7(5), 1-11. 
Arapitsas, P., Speri, G., Angeli, A., Perenzoni, D. \& Mattivi, F., 2014. The influence of storage on the "chemical age" of red wines. Metabolomics. $10,816-32$

Atanasova, V., Fulcrand, H., Cheynier, V. \& Moutounet, M., 2002. Effect of oxygenation on polyphenol changes occurring in the course of winemaking. Anal. Chim. Acta. 458(1), 15-27.

Bertrand, A. \& Barbe, J.C., 2002. Formation of $\gamma$-gluconolactone in a winelike model system. J. Sci. Food Agric. 82(13), 1571-3.

Bimpilas, A., Tsimogiannis, D., Balta-Brouma, K., Lymperopoulou, T. \& Oreopoulou, V., 2015. Evolution of phenolic compounds and metal content of wine during alcoholic fermentation and storage. Food Chem. 178, 164 71.

Bindon, K.A., Smith, P.A. \& Kennedy, J.A., 2010. Interaction between Grape-Derived Proanthocyanidins and Cell Wall Material. 1 . Effect on Proanthocyanidin Composition and Molecular Mass. J. Agric. Food Chem. $58,2520-8$

Canals, R., Llaudy, C., Miquel, J. \& Fernando, C., 2008. Influence of the elimination and addition of seeds on the colour, phenolic composition and astringency of red wine. Am. J. Enol. Vitic. 226, 1183-90.

Carrascón, V., Vallverdú-Queralt, A., Meudec, E., Sommerer, N., Fernandez-Zurbano, P. \& Ferreira, V., 2018. The kinetics of oxygen and SO2 consumption by red wines. What do they tell about oxidation mechanisms and about changes in wine composition? Food Chem. 241, 206-14.

Castellari, M., Matricardi, L., Arfelli, G., Galassi, S. \& Amati, A., 2000. Level of single bioactive phenolics in red wine as a function of the oxygen supplied during storage. Food Chem. 69, 61-7.

Cerpa-Calderón, F.K. \& Kennedy, J.A., 2008. Berry integrity and extraction of skin and seed proanthocyanidins during red wine fermentation. J. Agric. Food Chem. 56(19), 9006-14.

Dallas, C., Ricardo-da-Silva, J.M. \& Laureano, O., 1996. Interactions of Oligomeric Procyanidins in Model Wine Solutions Containing Malvidin-3Glucoside and Acetaldehyde. J. Sci. Food Agric. 70(4), 493-500.

Danilewicz, J.C., 2007. Interaction of sulfur dioxide, polyphenols, and oxygen in a wine-model system: Central role of iron and copper. Am. J. Enol. Vitic. 58(1), 53-60.

Du Toit, W.J., Marais, J., Pretorius, I.S. \& Du Toit, M., 2006. Oxygen in must and wine: A review. SAJEV. 27(1), 76-94.

Es-Safi, N.E., Fulcrand, H., Cheynier, V. \& Moutounet, M., 1999. Studies on the acetaldehyde-induced condensation of (-)-epicatechin and malvidin 3-O-glucoside in a model solution system. J. Agric. Food Chem. 47(5), 2096-102.

Fulcrand, H., Cameira dos Santos, P.-J., Sarni-Manchado, P., Cheynier, V. \& Favre-Bonvin, J., 1996. Structure of new anthocyanin-derived wine pigments. J. Chem. Soc. 69, 60.

Garrido-Bañuelos, G., 2018. Factors influencing the colour and phenolic composition of Shiraz wine during winemaking. Stellenbosch University. (March).

González-Manzano, S., Rivas-Gonzalo, J.C. \& Santos-Buelga, C., 2004. Extraction of flavan-3-ols from grape seed and skin into wine using simulated maceration. Anal. Chim. Acta. 513, 283-9.

Guaita, M., Petrozziello, M., Panero, L., Tsolakis, C., Motta, S. \& Bosso, A., 2017. Influence of early seeds removal on the physicochemical, polyphenolic, aromatic and sensory characteristics of red wines from Gaglioppo cv. Eur. Food Res. Technol. 243, 1311-22.

He, F., Liang, N., Mu, L., Pan, Q., Wang, J., Reeves, M.J. \& Duan, C., 2012. Anthocyanins and Their Variation in Red Wines I. Monomeric Anthocyanins and Their Color Expression. Molecules. 17, 1571-601.
Hernández-Jiménez, A., Kennedy, J.A., Bautista-Ortín, A.B. \& GómezPlaza, E., 2012. Effect of Ethanol on Grape Seed Proanthocyanidin Extraction. Am. J. Enol. Vitic. 63, 57-61.

Jorgensen, E., Marin, A. \& Kennedy, J.A., 2004. Analysis of the oxidative degradtion of proanthocyanidins under basic conditions. J. Agric. Food Chem. 52, 2292-6.

Lee, J., Kennedy, J.A., Devlin, C., Redhead, M. \& Rennaker, C., 2008. Effect of early seed removal during fermentation on proanthocyanidin extraction in red wine : A commercial production example. Food Chem. 107, 1270-3.

Lucci, P., Saurina, J. \& Núñez, O., 2017. Trends in LC-MS and LC-HRMS analysis and characterization of polyphenols in food. TrAC. 88, 1-24.

Mattivi, F., Vrhovsek, U., Masuero, D. \& Trainotti, D., 2009. Differences in the amount and structure of extractable skin and seed tannins amongst red grape varieties. Aust. J. Grape Wine R. 15, 27-35.

McRae, J.M., Day, M.P., Bindon, K.A., Kassara, S., Schmidt, S.A., Schulkin A., Kolouchova, R. \& Smith, P.A., 2015. Effect of early oxygen exposure on red wine colour and tannins. Tetrahedron. 71(20), 3131-7.

Meyer, B.J. \& Hernandez, R., 1970. Seed Tannin Extraction in Cabernet Sauvignon. Am. J. Enol. Vitic. 21, 184-8.

Monagas, M., Bartolomé, B. \& Gómez-Cordovés, C., 2005. Updated knowledge about the presence of phenolic compounds in wine. Crit. Rev. Food Sci. Nutr. 45, 85-118

Monagas, M., Gómez-Cordovés, C. \& Bartolomé, B., 2006. Evolution of the phenolic content of red wines from Vitis vinifera $\mathrm{L}$. during ageing in bottle. Food Chem. 95, 405-12.

Pérez-Magariño, S. \& González-SanJosé, M.L., 2004. Evolution of flavanols, anthocyanins, and their derivatives during the aging of red wines elaborated from grapes harvested at different stages of ripening. J. Agric. Food Chem. 52(5), 1181-9.

Peyrot Des Gachons, C. \& Kennedy, J.A., 2003. Direct Method for Determining Seed and Skin Proanthocyanidin Extraction into Red Wine. J. Sci. Food Agric. 51, 5877-81.

Picariello, L., Gambuti, A., Picariello, B. \& Moio, L., 2017. Evolution of pigments, tannins and acetaldehyde during forced oxidation of red wine: Effect of tannins addition. LWT-Food Sci. Technol. 77, 370-5.

Poncet-Legrand, C., Doco, T., Williams, P. \& Vernhet, A., 2007. Inhibition of grape seed tannin aggregation by wine mannoproteins: Effect of polysaccharide molecular weight. Am. J. Enol. Vitic. 58(1), 87-91.

Prakash, S., Iturmendi, N., Grelard, A., Moine, V. \& Dufourc, E., 2016. Quantitative analysis of Bordeaux red wine precipitates by solid-state NMR : Role of tartrates and polyphenols. Food Chem.199, 229-37.

Quaglieri, C., Jourdes, M., Waffo-Teguo, P. \& Teissedre, P.L., 2017. Updated knowledge about pyranoanthocyanins: Impact of oxygen on their contents, and contribution in the winemaking process to overall wine color. Trends Food Sci. Technol. 67(July), 139-49.

Raposo, R., Ruiz-Moreno, M.J., Garde-Cerdán, T., Puertas, B., MorenoRojas, J.M., Gonzalo-Diago, A., Guerrero, R.F., Ortiz, V. \& Cantos-Villar, E., 2016. Effect of hydroxytyrosol on quality of sulfur dioxide-free red wine. Food Chem. 192, 25-33.

Ribéreau-Gayon, P., Glories, Y., Maujean, A. \& Dubourdieu, D., 2006. Handbook of Enology. Volume 2. The chemistry of wine. Stabilization and treatments. John Wiley \& Sons, LTD.

De Rosso, M., Panighel, A., Vedova, A.D., Gardiman, M. \& Flamini, R., 2015. Characterization of non-anthocyanic flavonoids in some hybrid red grape extracts potentially interesting for industrial uses. Molecules. 20(10), 18095-106 
Sacchi, K.L., Bisson, L.F. \& Adams, D.O., 2005. A review of the effect of winemaking techniques on phenolic extraction in red wines. Am. J. Enol. Vitic. 56(3), 197-206.

Sarneckis, C.J., Dambergs, R.G., Jones, P., Mercurio, M., Herderich, M.J. \& Smith, P.A., 2006. Quantification of condensed tannins by precipitation with methyl cellulose: Development and validation of an optimised tool for grape and wine analysis. Aust. J. Grape Wine R. 12(1), 39-49.

Saucier, C., Bourgeois, G., Vitry, C., Roux, D. \& Glories, Y., 1997. Characterization of $(+)$-Catechin-Acetaldehyde Polymers: A Model for Colloidal State of Wine Polyphenols. J. Agric. Food Chem. 45(4), 1045-9.

Singleton, V.L. \& Trousdale, E.K., 1992. Anthocyanin-Tannin Interactions Explaining differences in polymeric phenols between white and red wines. Am. J. Enol. Vitic. 43, 63-70.

Smith, P.A., McRae, J.M. \& Bindon, K.A., 2015. Impact of winemaking practices on the concentration and composition of tannins in red wine. Aust. J. Grape Wine R. 21, 601-14.

Sparrow, A.M., Dambergs, R.G., Bindon, K.A., Smith, P.A. \& Close, D.C., 2015. Interaction of Grape Skin, Seed, and Pulp Tissues on Tannin and Anthocyanin Extraction in Pinot noir Wines. Am. J. Enol. Vitic. 1-27.

Springer, L.F., Chen, L.A., Stahlecker, A.C., Cousins, P. \& Sacks, G.L., 2016. Relationship of Soluble Grape-Derived Proteins to Condensed Tannin Extractability during Red Wine Fermentation. J. Agric. Food Chem. 64(43), 8191-9.
Timberlake, C.F. \& Bridle, P., 1977. Anthocyanins : Colour Augmentation with Catechin and Acetaldehyde. J. Sci. Food Agric. 28, 539-44.

Vallverdú-Queralt, A., Meudec, E., Eder, M., Lamuela-Raventos, R.M., Sommerer, N. \& Cheynier, V., 2017. The Hidden Face of Wine Polyphenol Polymerization Highlighted by High-Resolution Mass Spectrometry. ChemistryOpen. 6(3), 336-9.

Waters, E.J., Peng, Z., Pocock, K.F., Jones, G.P., Clarke, P. \& Williams, P.J., 1994. Solid-State13C NMR Investigation into Insoluble Deposits Adhering to the Inner Glass of Surface Bottled Red Wine. J. Agric. Food Chem. 42(8), $1761-6$

Watrelot, A.A., Schulz, D.L. \& Kennedy, J.A., 2017. Wine polysaccharides influence tannin-protein interactions. Food Hydrocoll. 63, 571-9.

Worley, B. \& Powers, R., 2016. PCA as a practical indicator of OPLS-DA model reliability. HHS Public Access. 4(2), 97-103.

Yacco, R.S., Watrelot, A.A. \& Kennedy, J.A., 2016. Red Wine Tannin Structure-Activity Relationships during Fermentation and Maceration. J. Agric. Food Chem. 64, 860-9.

Zeng, L., Teissèdre, P.L. \& Jourdes, M., 2016. Structures of polymeric pigments in red wine and their derived quantification markers revealed by high-resolution quadrupole time-of-flight mass spectrometry. Rapid Commun. in Mass Spectrom. 30(1), 81-8. 